\title{
Correction to: Effects of fermentation and drying durations on the quality of cocoa (Theobroma cacao L.) beans during the rainy season in the Juaboso District of the Western-North Region, Ghana
}

Emmanuel Ackah ${ }^{1 *}$ and Eric Dompey ${ }^{2}$

Correction to: Bull Natl Res Cent (2021) 45:175

https://doi.org/10.1186/s42269-021-00634-7

Following publication of the original article [1], the authors identified that figures and captions do not match. The correct Figs. 1, 2, 3 and 4 and captions are given below.
The original article Ackah and Dompey (2021) has been corrected. 

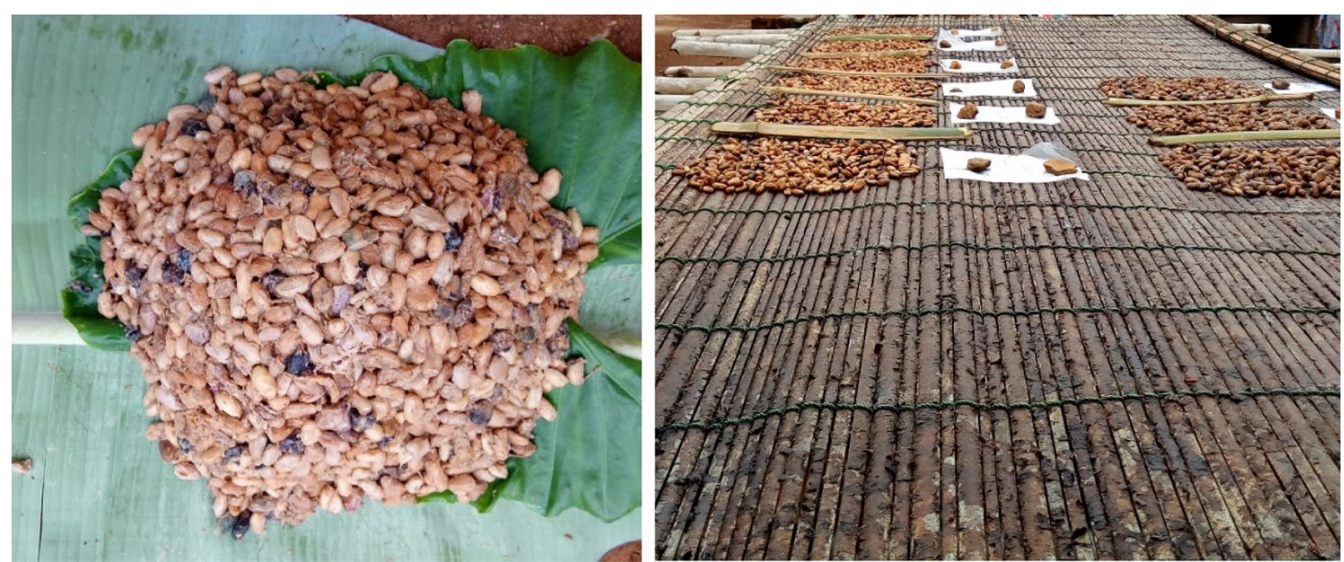

Fig. 1 Fermentation and drying of sampled cocoa beans with traditional leaf heap method and sun drying
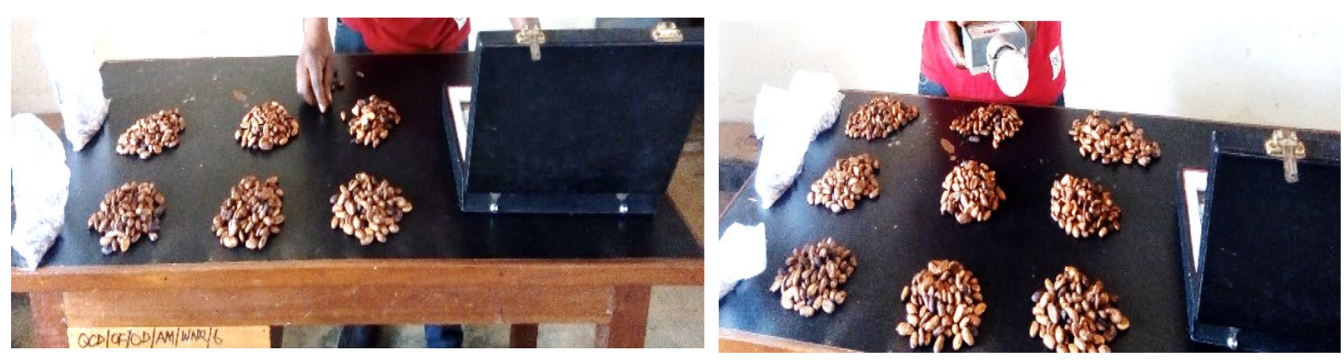

Fig. 2 Bean count and determination of moisture content with moisture meter aquaboy
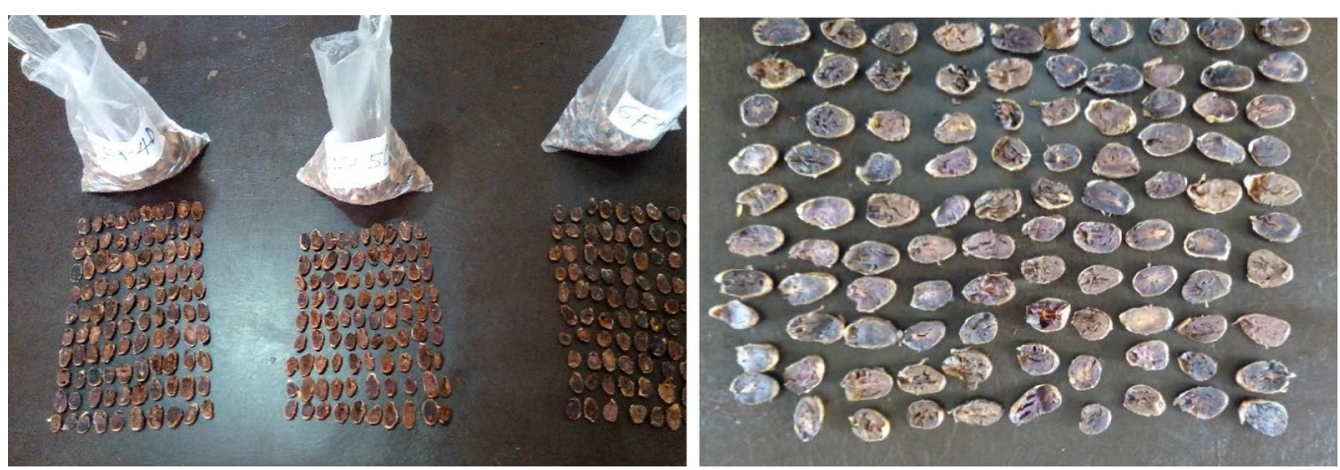

Fig. 3 Cross-longitudinal section of cut cocoa beans for identifying defective beans after storage 


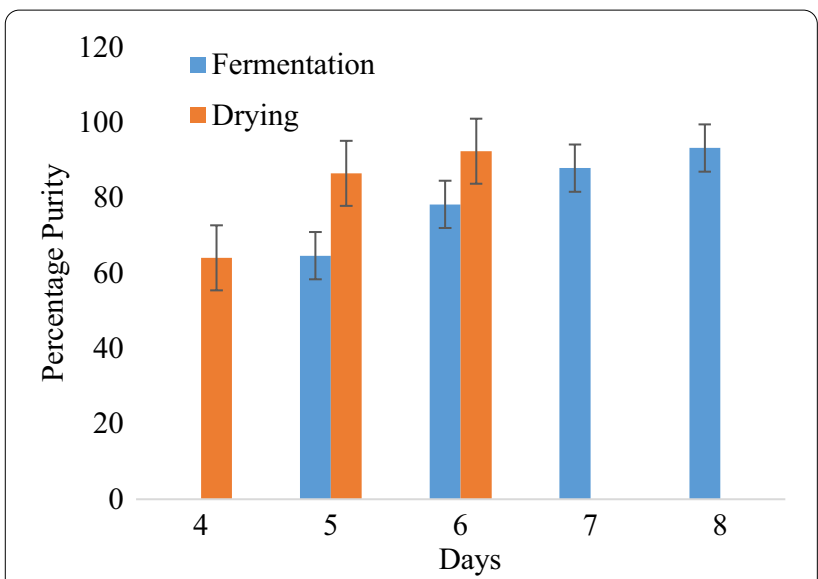

Fig. 4 Levels of cocoa bean purity as influenced by different fermentation and drying durations
${ }^{1}$ Department of Crop and Soil Science, College of Agriculture Education, University of Education, Winneba, Ashanti-Mampong, Ghana. ${ }^{2}$ Department of Agronomy, University of College of Agriculture and Environmental Studies, Bunso, Ghana.

Published online: 02 November 2021

\section{Reference}

Ackah E, Dompey E (2021) Effects of fermentation and drying durations on the quality of cocoa (Theobroma cacao L.) beans during the rainy season in the Juaboso District of the Western-North Region, Ghana. Bull Natl Res Cent 45:175. https://doi.org/10.1186/s42269-021-00634-7

\section{Publisher's Note}

Springer Nature remains neutral with regard to jurisdictional claims in published maps and institutional affiliations.

Author details 